\title{
Aspectos do trabalho e os distúrbios osteomusculares de trabalhadoras em um lactário de escola
}

\author{
Janaína Bussola Montrezor Valença, Maria do Carmo Baracho de Alencar \\ Universidade Federal de São Paulo - UNIFESP, Campus Baixada Santista, Santos, SP, Brasil.
}

\begin{abstract}
Resumo: Objetivo: Investigar sobre as condições de trabalho e ocorrência de distúrbios osteomusculares no trabalho de lactaristas de uma escola pública infantil. Método: Trata-se de um estudo ergonômico e um estudo de caso. Realizou-se levantamento de dados gerais sobre a escola e o local de trabalho. Aplicação de questionário às lactaristas, contendo informações pessoais, sobre o trabalho e sintomas osteomusculares. Levantamento de tarefas e processos de trabalho, observações sistemáticas e registros das atividades de trabalho, em papel e caneta, com base na metodologia da Análise Ergonômica do Trabalho (AET). Resultados: No local havia duas lactaristas que participaram do estudo, idade de 43 e 49 anos. Foram relatados sintomas osteomusculares nos últimos doze meses em região de punhos, mãos e coluna lombar; e nos últimos sete dias em coluna cervical e lombar. Constataram-se diversas condições inadequadas de trabalho, entre elas relacionadas ao espaço físico e ambiente térmico, e aspectos da organização do trabalho (equipe subdimensionada, horários de entrega de alimentos, entre outros). Conclusão: Aspectos precários das condições de trabalho tendem a favorecer o surgimento e/ou agravamento de distúrbios osteomusculares em lactaristas de escolas públicas infantis, e investigações visando à prevenção e promoção da saúde são necessárias.
\end{abstract}

Palavras-chave: Saúde do Trabalhador, Alimentação, Ergonomia, Escolas, Terapia Ocupacional.

\section{Working aspects and musculoskeletal disorders of workers in a school's lactary}

\begin{abstract}
Objective: To investigate the working conditions and the occurrence of musculoskeletal disorders in cooks from a Primary Public School. Method: This is an ergonomic study and a case study. General data about the school and the workplace were surveyed. A questionnaire was applied to cooks to collect information on personal and work aspects and musculoskeletal symptoms. Tasks and work processes, systematic observations and records of work activities were noted in paper, as based on the methodological approach of Ergonomic Work Analysis (EWA). Results: Two cooks participated in the study. They were 43 and 49 years old. They reported musculoskeletal symptoms in the region of wrist, hands, and low back in the last 12 months; and in the cervical and low back in the last seven days. Several inappropriate working conditions were found, including some related to the physical space and thermal environment, as well as aspects of work organization (undersized team, time for delivery of foods, etc.). Conclusion: Precarious working conditions tend to favor the emergence and/or worsening of musculoskeletal disorders in cooks of Primary Public Schools, and further research aimed at prevention and health promotion are necessary.
\end{abstract}

Keywords: Occupational Health, Feeding, Ergonomics, Schools, Occupational Therapy. 


\section{Introdução}

O trabalho ocupa um lugar central na vida de muitas pessoas e apresenta múltiplos significados pessoais e sociais. Nas vivências que ocorrem no trabalho há diferenças entre a tarefa prescrita e o trabalho real. O trabalho prescrito é definido como um conjunto de condiçôes e exigências a partir das quais o trabalho deverá ser realizado, ou seja, incluindo tanto as condições dadas para a execução de um trabalho (ambiente físico, matéria-prima, condições socioeconômicas), como as prescriçóes propriamente ditas (normas, ordens, resultados exigidos) (BENDASSOLI; SOBOLL, 2011). Já o trabalho real é o próprio momento de execução, é aquilo que é realmente colocado em ação pelo trabalhador (DEJOURS, 2008). De acordo com Dejours (2004), o real do trabalho envolve aquilo que em uma tarefa não pode ser obtido pela execução rigorosa do prescrito, devendo ser ajustado, rearranjado, imaginado, incidindo sobre a dimensão humana no trabalho. Para o autor, o prescrito no trabalho é realizado pela ação real do trabalhador.

A Ergonomia francófona, que privilegia a análise da atividade situada (expressão da interação dinâmica entre o sujeito e a tarefa), esforça-se em demonstrar que o trabalho prescrito jamais corresponde ao trabalho real, pois ao realizar uma tarefa, o trabalhador se depara com diversas fontes de variabilidade, desde as mais técnicas até as mais subjetivas; entre o trabalhador e a tarefa há portanto um terceiro elemento: a atividade de trabalho, que consiste justamente na realização (sempre singular) de um trabalho (SILVA; RAMMINGER, 2014). $\mathrm{E}$ a ação ergonômica visa eliminar ou limitar os efeitos indesejáveis que afetam o operador ou a tarefa (FALZON, 2007).

De acordo com Anjos e Mendes (2015), há uma infinidade de possibilidades diferentes das previstas pela prescrição que podem ocorrer no momento da execuçấo: ineditismos, imprevistos, contradições, ambivalências, etc. Uma análise do trabalho real não pode prestar atenção somente ao que o trabalhador faz, mas também ao que ele não consegue fazer, o que ele gostaria, poderia e o que deveria fazer (HUBALT; SZNELWAR, 2012). E diante de situaçôes com constrangimentos no trabalho, o trabalhador utiliza estratégias de regulação. $\mathrm{Na}$ regulação da atividade humana, o operador tem em vista evitar repercussóes negativas da atividade nele mesmo e atingir os objetivos da tarefa (FALZON, 2007).

Os modos de organizaçáo do trabalho mudaram muito ao longo dos anos e muitas consequências decorreram dessas mudanças, e diferentes formas de adoecimento no trabalho emergem de respostas que o ser humano dá aos conflitos e sofrimentos vivenciados pelos trabalhadores. As lesões por esforços repetitivos (LER)/distúrbios osteomusculares relacionados ao trabalho (DORT) são uma das formas de adoecimento no mundo do trabalho, e apresentam prejuízos econômicos para a sociedade e custos elevados de tratamento em vários países, além de serem vistos como um dos maiores problemas de saúde pública no mundo (GALLAGHER; HEBERGER, 2013; MACDONALD; OAKMAN, 2015). As LER/DORT vêm assumindo um dos principais grupos de agravos à saúde entre as doenças ocupacionais (CARUGNO et al., 2012). Esse grupo de transtornos tem o aparecimento e evoluçáo de caráter insidioso, e origens multifatoriais complexas (BRASIL, 2012). As LER/DORT não se encaixam em paradigma médico de interpretação do processo saúde-doença baseado em uma causalidade linear, daí a necessidade de conhecer e valorizar as abordagens integradoras que considerem não só o caráter físico e biológico, mas também o contexto geral da doença (CHIAVEGATTO; PEREIRA, 2004). As várias formas clínicas de manifestação das LER/DORT têm como aspecto comum a dor, que afeta o cotidiano de vida dos sujeitos, e não somente a do trabalho, decorrente de incapacidades funcionais que podem ser permanentes e/ou temporárias (BRASIL, 2012).

Sáo vários os estudos que abordam a presença de distúrbios osteomusculares relacionados ao trabalho em cozinhas (NEGRI et al., 2014; SOUZA; SILVEIRA, 2011; ISOSAKI et al., 2011; TAKAHASHI; PIZZI; DINIZ, 2010; MONTEIRO, 2009). Em estudo de Negri et al. (2014), entre as profissóes mais acometidas por LER/DORT está a profissão de cozinheiro. Alencar, Cavalcanti e Montrezor (2013) relataram que as cozinheiras em suas tarefas realizavam movimentos repetitivos de membros superiores e coluna, com levantamento de pesos, permanência prolongada na postura em pé e em risco de acometimento por LER/DORT. Trabalhadores em cozinhas são submetidos a condiçôes inadequadas de trabalho, contendo ruído, calor, umidade, risco de acidentes, esforço físico e/ou mental, ritmo de trabalho intenso, monótono e repetitivo, em posturas estáticas que podem levar à fadiga física, ao estresse e às doenças ocupacionais (ISOSAKI et al., 2011). E as condiçóes de trabalho das merendeiras (assim denominadas as cozinheiras em escolas) são bem difíceis, necessitando que elas driblem as adversidades existentes, como escassez e inadequação de utensílios, a altura do fogão, pias e tanques inadequados, e quantidade de trabalho elevada (SILVA; BRITO; ATHAYDE, 2004). De acordo com Carvalho et al. (2008), há 
sobrecargas no trabalho das merendeiras, que vão além da preparação das refeiçôes, como o cuidado do aluno em determinadas situaçóes, preocupação com a aceitação das preparaçóes, limpeza do refeitório, entre outros.

Algumas escolas públicas infantis podem atender crianças de 0 a 12 meses, apresentando nesses locais berçários e lactários. Há poucos estudos nacionais relacionados ao trabalho em lactários, especialmente em escolas públicas. A Secretaria Municipal da Educação do Estado de São Paulo, através das Normas e Padrôes Básicos para Lactários (BRASIL, 2010), define lactário como uma área específica destinada à elaboração de fórmulas lácteas infantis, sucos, papas de frutas, papas salgadas e leite integral servido na mamadeira para criança acima de 1 ano, que náo tenha completado a transição para a caneca; além de distribuição das refeiçôes, higienização, armazenamento de utensílios, entre outros. Segundo este documento, em relação à edificação e instalaçóes, estas devem garantir conforto ambiental, que compreende a ventilação, iluminação e fluxo ordenado do processo de produção de alimentos. Em lactários ocorre comumente a preparação de dietas especiais, que exige procedimentos tecnicamente diferenciados, $o$ que gera preocupaçóes nos trabalhadores (GARCIA, 2006). Em estudo realizado nos setores do lactário e da cozinha dietética de um hospital, foram encontrados problemas como área física-ambiência deficiente, gêneros alimentícios de baixa qualidade e fornecidos em quantidade insuficientes, além de relacionamentos conflituosos com superiores hierárquicos (BERTIN et al., 2009).

$\mathrm{O}$ objetivo deste estudo foi investigar sobre as condiçôes de trabalho e ocorrência de distúrbios osteomusculares no trabalho de lactaristas de uma escola pública infantil.

\section{Método}

Trata-se de um estudo ergonômico e um estudo de caso realizado em uma escola pública infantil, localizada na Baixada Santista (SP), que contava, além de uma cozinha industrial, com um lactário para crianças com até 2 anos de idade. Essa escola tinha cozinheiras que trabalhavam na cozinha industrial e eram responsáveis pela merenda escolar; e também lactaristas, foco deste estudo, que trabalhavam no lactário da escola. Primeiramente, apresentou-se o projeto de estudo para aprovação pelo Órgão Municipal local responsável, o qual sugeriu, após a aprovação, a escola pública infantil da Baixada Santista para a realização do estudo. O estudo utilizou a abordagem metodológica da Análise Ergonômica do Trabalho (AET) e teve início no ano de 2011, sendo concluído no ano de 2012.

O estudo foi realizado em duas etapas. Na primeira etapa fez-se o levantamento de informaçôes sobre o trabalho no lactário e ambiente físico, como: o número total de lactaristas, de crianças atendidas, horários de trabalho, horários das refeições e entregas de produtos/alimentos, características do espaço físico (dimensôes, equipamentos utilizados, etc.), tarefas prescritas, entre outros. Esses dados foram fornecidos pelas próprias trabalhadoras, e também pela direção da escola. Em seguida, foi elaborado e aplicado um questionário sob forma de entrevista, como complemento às lactaristas e visando conhecer o trabalho prescrito, contendo: dados pessoais (idade, gênero, estado civil, escolaridade); questôes relacionadas ao trabalho, tais como: profissão atual, profissão anterior, tempo de atuação na profissão e na escola, carga horária de trabalho, tarefas realizadas, etc.; e questōes relacionadas à presença e frequência de sintomas osteomusculares, regióes acometidas, história prévia de lesões, entre outros.

$\mathrm{Na}$ segunda etapa do estudo ocorreram observaçóes globais (no período de visitas ao lactário e conversas abertas com as lactaristas), seguidas de observaçóes sistemáticas e registros de atividades de trabalho, sendo a observação e a análise do trabalho executadas em condiçôes reais (não simuladas), revelando a atividade concreta de trabalho e a interlocução com os diferentes atores do trabalho (trabalho real). As observaçóes ocorreram duas vezes por semana, durante um período de três meses, em turnos alternados (manhã e tarde). Durante as observações foram registrados com papel e caneta comentários ou expressóes verbais das lactaristas em relação ao trabalho, além de outros aspectos relevantes ao estudo. As informaçóes obtidas em visitas iniciais e primeiros contatos com as lactaristas indicaram maiores queixas de sintomas osteomusculares no preparo dos alimentos, entrega e armazenamento dos alimentos, por isso o delineamento e o maior destaque para esse estudo.

Após as análises dos resultados encontrados, também ocorreram dois encontros com as trabalhadoras (lactaristas), com duração aproximada de 55 minutos em cada encontro, que foi realizado no próprio local de trabalho, sem ônus às trabalhadoras e em horário acordado, para discussóes sobre a análise dos dados obtidos e validação; e também foram propostas sugestóes para melhorias. Um relatório final foi apresentado à direção da escola, com o diagnóstico e as sugestóes para melhorias.

O estudo foi submetido e aprovado pelo Comitê de Ética em Pesquisa da Universidade Federal de 
São Paulo - UNIFESP (protocolo n 2097/11) e seguiu todos os procedimentos éticos necessários para a sua execução. Todos os sujeitos que aceitaram participar do estudo assinaram o Termo de Consentimento Livre e Esclarecido (TCLE).

\section{Resultados e Discussão}

A escola municipal estudada foi fundada pela Prefeitura de uma cidade da Baixada Santista no ano de 2009. Na ocasiáo do estudo, no berçário da escola ficavam vinte (20) crianças, de ambos os gêneros, divididas em duas turmas (A e B), sendo dez (10) crianças em cada uma das turmas e com faixa etária que variou de quatro (4) meses a um (1) ano e quatro (4) meses. Duas lactaristas e também cozinheiras (gênero feminino) eram responsáveis por desempenhar todas as tarefas no lactário do berçário. Ambas possuíam idade superior a 40 anos ( 43 e 49 anos de idade), escolaridade de ensino médio completo, com tempo de atuação como cozinheira em escolas superior a 10 anos, e tempo de atuaçáo no lactário de 2 a 3 anos, e apresentavam jornada de trabalho de 8 horas/dia em turno diurno.

As lactaristas relataram presença de distúrbios osteomusculares, sendo as regióes em comum acometidas nos últimos doze meses que antecederam este estudo: punhos, mãos e região lombar; e nos sete dias anteriores ao estudo nas regióes cervical e lombar. Referiram também sintomas dolorosos em membros inferiores. Alguns estudos demonstram queixas de dores entre cozinheiros, principalmente na regiáo lombar, braços, punhos, máos e dedos, e atribuem a movimentos inadequados realizados para membros superiores e força manual excessiva (SOUZA; SILVEIRA, 2011; TAKAHASHI; PIZZI; DINIZ, 2010). Em estudo com trabalhadores de um serviço de Nutrição Hospitalar, as regiōes corporais mais citadas nos últimos doze meses foram: membros inferiores, ombros e coluna lombar (ISOSAKI et al., 2011).

Outros dados foram obtidos por meio do questionário inicial aplicado: nenhuma das lactaristas apresentou história de lesão osteomuscular prévia antes de iniciar o trabalho como cozinheira, e não procuraram por atendimento médico ou houve licença do trabalho por causa desses sintomas dolorosos nos doze meses que antecederam este estudo. Porém, uma lactarista (Cozinheira 1) já havia se afastado do trabalho por sintomas dolorosos em região de punho, mãos e dedos em período anterior (quando trabalhava como cozinheira em escola). As lactaristas foram contratadas após aprovação em concurso público, como cozinheiras, sendo funcionárias estatutárias, o que lhes garantia estabilidade no emprego, mas não a garantia de estar na mesma escola (podiam eventualmente ser transferidas para outra unidade escolar ou creche). Ambas receberam treinamento para atuar em lactários e eram supervisionadas por uma nutricionista semanalmente, e também pela diretora da escola.

As principais tarefas das lactaristas eram: pré-preparo e preparo de refeiçôes (incluindo o preparo das mamadeiras, corte e trituração de alguns alimentos para as refeiçôes dos bebês), distribuição das refeiçôes, higienização, recebimento e armazenamento de produtos alimentícios e utensílios, e limpeza do lactário. Para este estudo não foi analisada a tarefa de limpeza do lactário.

Em relação ao espaço físico de trabalho, as lactaristas dispunham do lactário e de uma despensa, sendo que esta última não pertencia ao lactário e sim à cozinha da escola, o que exigia deslocamentos até o local, pois no lactário não havia espaço suficiente para o armazenamento de todos os alimentos necessários. O lactário era retangular e estreito, apresentava duas janelas pequenas dispostas na parede da pia, duas portas de saída, uma pia com três cubas, um fogão de quatro bocas, uma geladeira, ao lado da qual se encontravam quatro prateleiras (uma embaixo da outra) onde eram guardados alguns temperos, pratos de vidro, bandejas, talheres e utensílios de uso diário no trabalho, como concha, escumadeira, amassador de alho, entre outros equipamentos. A Figura 1 ilustra o espaço físico do lactário.

A iluminação contava com duas luminárias no teto; e havia também um ventilador que não era usado por náo estar adequado. Entre os equipamentos utilizados estavam: um espremedor de frutas, um liquidificador e uma centrífuga, além de uma panela especial para esterilização dos materiais usados. $\mathrm{Na}$ despensa da cozinha da escola havia prateleiras de concreto nas paredes, onde eram armazenados os alimentos não perecíveis: arroz, farinha, feijão, óleo, caixas de leite, molhos de tomate, achocolatado em pó, entre outros, e separados entre o que pertencia à alimentação das crianças da escola e o que pertencia à alimentaçáo dos bebês do lactário.

As refeições e horários do lactário eram programados: lanche da manhã, suco, almoço, lanche da tarde e jantar, cabendo às educadoras infantis o papel da alimentação. Os horários estabelecidos para as refeiçóes eram: 07:30h - servir as mamadeiras; 09:10h - servir um suco ou frutas; $10: 30 \mathrm{~h}$ - servir o almoço; 12:30 - servir mamadeiras (lanche da tarde); $15: 30 \mathrm{~h}$ - servir o jantar. 


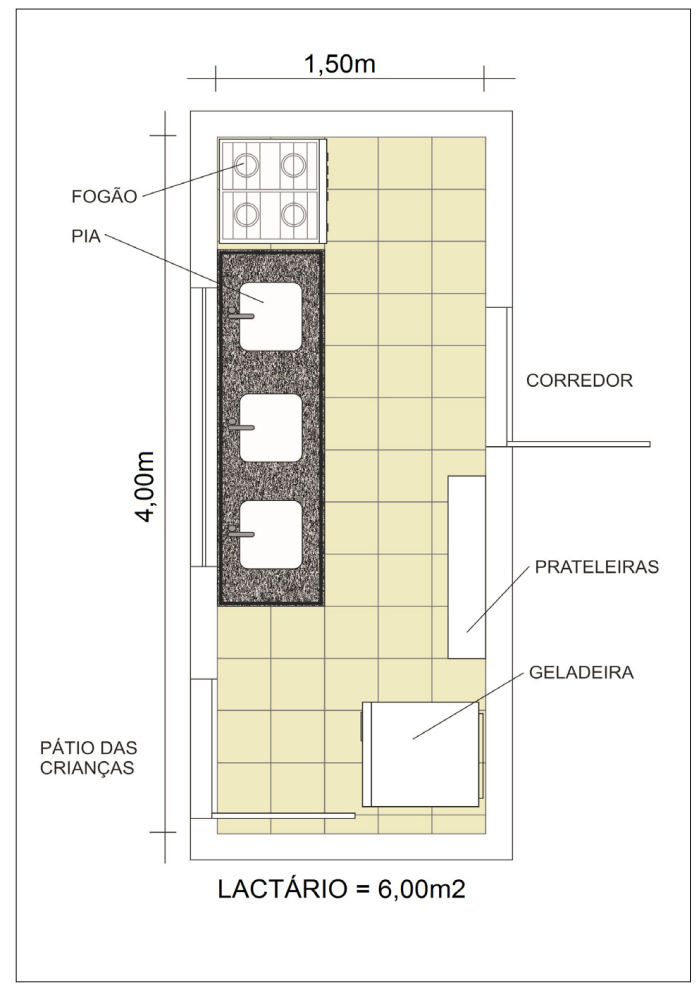

Figura 1. Espaço físico do lactário.

O cardápio variava toda semana, conforme orientação da nutricionista e médicos (algumas crianças necessitavam de dieta alimentar diferenciada) e conforme os alimentos que chegavam da feira, que eram entregues semanalmente na escola. Quanto à pausa para o almoço, era acordado entre elas cerca de 30 a 40 minutos.

\subsection{O preparo e a distribuição das refeições}

O preparo das refeiçóes envolvia desde a preparação e separação dos utensílios necessários, colocação dos alimentos em panelas, o mexer e remexer os alimentos, entre outros, acompanhando o cozimento até o final, e o preparo das mamadeiras. No preparo das refeiçóes havia diferenciações, sendo determinados alimentos pastosos para crianças menores e alimentos mais sólidos para as crianças maiores. Ao preparar as mamadeiras com leite, era necessário planejamento, atenção, memória e concentraçáo, entre outras exigências cognitivas. Todas as mamadeiras eram preparadas ao mesmo tempo, para garantir o cumprimento dos horários estabelecidos para servi-las e evitar os choros e desgaste das crianças com esperas. Cuidados no preparo em relação à temperatura das mamadeiras, ao tipo de leite para algumas crianças (algumas crianças eram intolerantes à lactose e necessitavam de um tipo diferente de leite), e a identificação das mamadeiras era necessária, como no relato:

\section{[...] Tem crianças com diferencial, uma não pode com lactose, outra é outro tipo de leite que o médico passou, outra para refluxo (Cozinheira 1).}

Alguns cuidados eram necessários no preparo das mamadeiras e que geravam preocupaçôes e desgaste. Era importante considerar a idade de cada criança, havendo exigências específicas em alguns casos, aspecto também encontrado no preparo de outras refeições (especialmente sopas), como no relato:

\section{[...] Tem problema com comida também, tem criança que não pode comer abóbora e cenoura... tem que fazer a comida separado (Cozinheira 1).}

Havia uma preocupação em relação à atenção e memorização necessária no preparo das refeições diferenciadas, especialmente pelos riscos à saúde dos bebês e suas consequências. Deve-se considerar que na faixa etária de 0 a 2 anos ocorrem mudanças nos padróes alimentares, por exemplo, a passagem da amamentação para introdução de outros líquidos, alimentos pastosos, entre outros. Houve modificaçóes dos modos operatórios que foram ditadas pelas variabilidades impostas pelos processos, especialmente relacionadas ao ritmo de trabalho, e que afetaram as posturas e os movimentos corporais das trabalhadoras. O tempo é um dos elementos essenciais que intervém na determinação dos modos operatórios, e conforme as situaçóes de trabalho, a pressão temporal resulta em vários constrangimentos (GUÉRIN et al., 2007). O tronco era muitas vezes mantido com inclinação sobre a pia, e as execuçôes manuais de cortes de alimentos eram em geral feitas com rapidez e força muscular, e com ausência de pausas no período da manhã, além da permanência na postura em pé. Geralmente as atividades dentro das cozinhas são realizadas pela maioria dos trabalhadores na postura em pé (ALENCAR; CAVALCANTI; MONTREZOR, 2013).

O espaço físico era pequeno, e com o cozimento dos alimentos e a pouca ventilação, aumentava-se a temperatura interna, dificultando muitas vezes a permanência no local, como no relato:

\section{[...] eu sofro bastante com o calor (Cozinheira 2).}

Em estudo de Souza e Silveira (2011), as cozinheiras também relataram sofrer com as elevadas temperaturas provenientes da irradiação de calor dos equipamentos, devido à inadequação do ambiente físico de trabalho, causando desconforto principalmente na época do verão. Toda tarefa se 
desenvolve dentro de um contexto de exposição do operador ao microclima do posto, à iluminação deste, entre outros, sendo este meio ambiente de trabalho usualmente qualificado pelo termo de "ambiência física” (MILLANVOYE, 2007). A inadequação foi demonstrada nos relatos abaixo:

[...] É tão pequeno, que quando a panela está ligada muito tempo, escorre um suor nos azulejos de cima até embaixo (Cozinheira 2).

\section{[...] Não consigo ficar aqui dentro muito tempo, é muito quente (Cozinheira 1).}

De acordo com Monteiro (2009), apesar dos avanços tecnológicos que vêm sendo incorporados em unidades de alimentação e nutrição, em relação à matéria-prima, aos métodos de trabalho e aos equipamentos, os locais destinados ao preparo das refeiçôes ainda apresentam, em geral, condiçôes físicas inadequadas, como temperatura elevada, arranjo físico e instalações precárias, iluminação deficiente, que podem influenciar na produtividade e na saúde do trabalhador. Não havia adequada circulaçáo de ar, havia uma porta que abria para um corredor e tinha que ficar sempre fechada, devido à vizinhança com o fraldário, de onde exalava (se aberta), em determinados momentos, um cheiro de fezes de crianças, como demonstrado no relato:

[...] a porta tem que ficar fechada ... não dá para aguentar o cheiro (Cozinheira 2).

O ambiente físico de trabalho inadequado pode aumentar as exigências de trabalho, ocasionar desgaste e afetar a atividade de trabalho. $\mathrm{Na}$ falta de condiçóes de trabalho adequadas, o contexto de precarização configura-se em sobrecargas de trabalho (SILVA; BRITO; ATHAYDE, 2004).

Não havia balcôes e espaço livre para a organização e separação dos utensílios, e também para o melhor controle no preparo das dietas diferenciadas. As lactaristas dispunham apenas de uma pia para a realização dessas tarefas. Havia dificuldade na identificação das mamadeiras devido à falta de espaço físico, conforme observado e também no relato:

[...] não tem espaço, falta um balcão para a gente... quando a gente está fazendo as mamadeiras, tem que botar uma lá no canto e noutro canto, para a gente não se perder (Cozinheira 1).

Alguns aspectos de risco para o surgimento de distúrbios osteomusculares na preparação de alimentos foram observados, como a repetitividade de movimentos e posturas inadequadas:
[...] para lavar a panela depois, para amassar a sopa, no final do dia o braço tá bem dolorido (Cozinheira 2).

A lactarista 2 executava ainda tarefas na cozinha da escola no período da manhá, aspecto de risco para o agravamento dos sintomas, pois aumentavam as exigências de trabalho (tanto físicas quanto mentais), uma vez que ela atuava em dois locais e com diferentes contextos. Tarefas que exigem repetitividade ou esforço podem causar inflamaçóes agudas e dor, sendo as LER/DORT frequentes nesses casos; além da dor, pode ocorrer a perda da função motora, que contribui para a situação de afastamento do trabalho, além de consequências socioeconômicas e psicossociais (NEGRI et al., 2014). De acordo com Neves e Nunes (2010), muitos trabalhadores por medo de "deboches" ou demissão, ou por querer mostrar-se capaz e participativo, se calam em relaçáo aos seus sintomas dolorosos e trabalham com dor, agravando o quadro clínico. Ainda havia uma preocupação em não deixar as crianças sem alimentação, já que muitas delas eram de famílias de baixa renda, o que as fazia "ignorar" muitas vezes os sintomas osteomusculares.

Adequaçóes no espaço físico são importantes e fundamentais, pois facilitariam as adequaçóes posturais, mas não são totalmente determinantes para a prevenção de distúrbios osteomusculares. O corpo tem a capacidade de sentir e reagir, como um todo, na própria subjetividade (HUBALT; SZNELWAR, 2012). Partindo do pressuposto que o trabalho contém componentes motores, ideativos e afetivos, o homem pensa, age, sente, atua, aprende, etc., e adquire sentimentos referentes à atividade; e tanto o pensamento como os sentimentos e emoçóes possuem repercussóes motoras (OLIVEIRA, 2002).

Ainda no período do estudo havia apenas uma lactarista no período da manhá, pois a outra lactarista, durante esse período, tinha sido deslocada para auxiliar o trabalho na cozinha da escola, situação que já ocorria havia mais de um ano, devido ao número insuficiente de funcionários na cozinha da escola (uma das cozinheiras da escola estava em situação de afastamento do trabalho). Esta situação preocupava as lactaristas especialmente pela "impossibilidade" de faltar no trabalho, pois se preocupavam especialmente com as crianças e com o serviço. A escola atendia cerca de 260 crianças, fora as do berçário, e possuía quatro cozinheiras (incluindo a lactarista deslocada).

Em relação à distribuição das mamadeiras $\mathrm{e}$ outros alimentos, havia a preocupação de entregá-las antes que os bebês começassem a chorar por fome, 
nem sempre possível, devido a algumas ocorrências (como o fato de a entrega de mamadeiras não ocorrer simultaneamente, diferentes horários de fome dos bebês e alguns atrasos no preparo dos alimentos). As mamadeiras, eram normalmente dispostas de quatro a cinco em uma bandeja, e os alimentos sólidos dispostos em pratos, também servidos em uma bandeja, e eram entregues pelas lactaristas para as professoras, exigindo vários deslocamentos, e as professoras que alimentavam as crianças. Havia a preocupação de que náo houvesse a troca de mamadeiras na hora da entrega, como no relato:

\section{[...] a gente fica preocupada se vão dar a mamadeira} certa (Cozinheira 1).

Depois elas buscavam as mamadeiras, pratos e utensílios para serem lavados.

\subsection{O recebimento e armazenamento dos alimentos}

Quanto à entrega e armazenamento dos alimentos, na terça-feira chegavam os produtos da feira (legumes e frutas) no período da manhá; e na quinta ou sexta-feira, também no período da manhã, chegavam as carnes vermelhas e brancas. Outros alimentos industrializados chegavam uma vez ao mês. No lactário eram armazenados apenas os legumes, frutas e verduras e alguns alimentos como leite, bolacha, macarrão, arroz e chocolate em pó, que deviam ser trazidos da despensa para o lactário. Os demais alimentos industrializados e a carne eram armazenados na despensa da cozinha, em prateleiras. Algumas caixas eram armazenadas em prateleiras altas e retiradas com uso de escada.

Havia no lactário exigências para o cumprimento dos horários das refeiçôes, complicando a situação nos horários de entregas de produtos, que também ocorriam no período da manhă. Isso gerava desgaste para as trabalhadoras, conforme demonstrado no relato:

[...] a gente tem que parar o que está fazendo para receber as mercadorias, e às vezes só tem uma de nós aqui para fazer isso! (Cozinheira 1).

Para o início do preparo das refeiçóes, era necessário buscar os produtos que estavam na despensa da escola, exigindo deslocamento. A situação era agravada com a chegada dos produtos da feira, que ocorria entre 08:30h e 09:00h, horário em que a lactarista estava preparando os alimentos para o almoço, necessitando interromper o cozimento muitas vezes para se deslocar (com aproximadamente 50 metros de distância) e armazenar os alimentos nas prateleiras. $\mathrm{O}$ mesmo ocorria com as carnes, que chegavam entre 10:30h e 11:00h, coincidindo com o horário de servir o almoço e acelerava, portanto, o ritmo de trabalho. A aceleração dos movimentos para a execução da tarefa ocorre na tentativa de compensar o tempo supostamente perdido, podendo também favorecer descuidos posturais, aspectos que necessitam de maiores investigaçóes. De acordo com Fernandes, Assunção e Carvalho (2010), a aceleração do ritmo de trabalho ocorre à custa de hipersolicitação do sistema musculoesquelético, com adoção de posturas inadequadas que visam diminuir o tempo de execução da tarefa, e resulta da inter-relação complexa entre diversos fatores do trabalho e a regulação possível. Muitos alimentos ainda chegavam dentro de caixas pesadas, que eram transportadas manualmente por elas, e com descuidos posturais. E alguns utensílios utilizados no preparo de alimentos eram armazenados em prateleiras após o uso.

Ter uma equipe subdimensionada, ou ocorrer o deslocamento de trabalhadores em horários considerados "de pico" para a realização de outras tarefas, tende a sobrecarregar os trabalhadores tanto física quanto mentalmente, e pode gerar agravos à saúde ao longo do tempo, situaçáo que deve ser evitada e reorganizada para que não prejudique os trabalhadores. Em estudo de Alencar, Cavalcanti e Montrezor (2013), foram encontradas situaçóes em que houve o deslocamento de uma das cozinheiras de uma escola para atender às solicitaçóes da direção, em horário considerado por elas "de pico" (almoço das crianças), gerando sobrecargas para as demais trabalhadoras, em geral por acúmulo de tarefas.

Ainda, devido às exigências do trabalho em ritmo acelerado, nem sempre era possível "cuidar da postura", como no relato:

\section{[...] você não percebe que não está na postura correta (Cozinheira 1).}

As posturas inadequadas foram encontradas no transporte de caixas, no armazenamento de alimentos nas prateleiras e no preparo das sopas.

$\mathrm{Na}$ Tabela 1 encontram-se as tarefas prescritas e constrangimentos encontrados nas atividades de trabalho.

Muitas das açóes observadas e que visavam reparar os processos para atingir os objetivos desejados, envolveram desgaste, influenciaram nas exigências físicas e mentais, e tiveram relações com aspectos da organização do trabalho. As estratégias utilizadas pelas lactaristas nas atividades para alcançar os objetivos envolveram no geral o aumento de velocidade em 
Tabela 1. Tarefas e constrangimentos encontrados nas atividades de trabalho.

\begin{tabular}{|c|c|}
\hline TAREFAS & $\begin{array}{c}\text { CONSTRANGIMENTOS ENCONTRADOS } \\
\text { NAS ATIVIDADES }\end{array}$ \\
\hline 1. Preparo das refeições & $\begin{array}{l}\text { - Inadequação da ambiência física (pouca ventilação). } \\
\text { - Local inadequado para uma melhor identificação e cuidado nas } \\
\text { diferenciações das refeições necessárias (pastosas e líquidas). } \\
\text { - Chegada de alimentos e necessidade de interrupção de tarefas, } \\
\text { gerando atrasos. } \\
\text { - Deslocamento de trabalhadora, aumentando as sobrecargas para } \\
\text { uma delas. } \\
\text { - Pressão temporal com aumento do ritmo de trabalho, aumentando } \\
\text { a velocidade de movimentos, especialmente ao amassar e cortar } \\
\text { os legumes e frutas, aumentando o risco também de acidentes. }\end{array}$ \\
\hline 2. Distribuição das refeições & $\begin{array}{l}\text { - Preocupação com choros dos bebês e atrasos. } \\
\text { - Falta de equipamentos adequados que auxiliem na distribuição } \\
\text { das refeições. } \\
\text { - Pressão temporal com aumento do ritmo de trabalho, } \\
\text { especialmente pela manhã, aumentando a velocidade de algumas } \\
\text { ações e nos deslocamentos. }\end{array}$ \\
\hline $\begin{array}{l}\text { 3. Recebimento e armazenamento de } \\
\text { alimentos }\end{array}$ & $\begin{array}{l}\text { - A entrega dos alimentos não tem horário bem definido e obriga a } \\
\text { trabalhadora a interromper outras tarefas, gerando atrasos. } \\
\text { - Exigências de deslocamentos para o recebimento dos alimentos. } \\
\text { - Transporte manual de alimentos (caixas pesadas), sem uma } \\
\text { proximidade ao local. } \\
\text { - Necessidade de aceleração de ações e aumento de ritmo de } \\
\text { trabalho para compensar as interrupções. }\end{array}$ \\
\hline
\end{tabular}

ações, pela pressão temporal, havendo sobrecargas para o corpo.

\subsection{Validação e recomendações}

Houve condiçóes inadequadas de trabalho relacionadas ao ambiente e espaço físico, e alguns aspectos da organização do trabalho que podem influenciar no surgimento e/ou agravamento de distúrbios osteomusculares, em especial por haver história anterior de sintomas osteomusculares. Após as análises, os dados encontrados foram validados com as lactaristas e recomendaçóes de melhorias foram sugeridas.

Entre as recomendações para melhorias surgiram:

- Adequar minimamente o espaço físico ou mudar o lactário de local. Entre as mudanças necessárias: inclusão de balcão com espaço livre, local para armazenamento de alimentos de uso semanal, aumentar a largura das janelas. $\mathrm{Na}$ impossibilidade de mudança ou de aumentar o tamanho (espaço físico), mudar o fraldário de local, para que a porta possa ser aberta e melhorar a circulação do ar;
- Criar um espaço físico para o armazenamento dos produtos do lactário mais próximo do local;

- Melhorar a ambiência do local, em especial quanto à temperatura, e verificar a possibilidade de uso do ventilador e/ou de um exaustor;

- Resolver a situação de falta de funcionário na cozinha da escola, para evitar o deslocamento da cozinheira/lactarista no período da manhã;

- Ter uma cozinheira na cozinha da escola apta a trabalhar também no lactário, caso seja necessário;

- Um carrinho de transporte dos alimentos (tanto na entrega das mercadorias como para a entrega aos bebês);

- Reorganizar os horários de entregas de produtos alimentícios;

- Ter um funcionário para auxiliar no armazenamento e transporte dos produtos alimentícios no ato das entregas (na despensa), em especial com as caixas pesadas;

- Promover espaços de diálogos e discussóes com a Direção e Nutricionista a respeito das dificuldades encontradas no trabalho. 


\section{Conclusão}

As observações das atividades foram fundamentais para a identificação e compreensão de fatores que geravam constrangimentos no trabalho das lactaristas. AAET permite identificar as variabilidades do trabalho, evidenciando como ocorrem exigências extras que podem resultar em sobrecargas em determinadas cargas de trabalho. No caso, aspectos da organização de trabalho tiveram influências nas sobrecargas tanto físicas quanto mentais, podendo favorecer o agravamento dos sintomas osteomusculares dessas trabalhadoras. Ainda, espera-se que este estudo possa colaborar com futuros estudos relacionados ao trabalho de lactaristas em escolas públicas infantis.

\section{Limitações do Estudo}

Não se pretendeu com este estudo caracterizar o trabalho de lactaristas em lactários de escolas, nem de investigar todos os processos de trabalho, mas sim trazer alguns aspectos analisados no trabalho em um desses locais. A análise de um único local fornece fragilidades à generalização, portanto, futuros estudos devem ser realizados nesses locais.

\section{Referências}

ALENCAR, M. C. B.; CAVALCANTI, T. A.; MONTREZOR, J. B. Condiçóes de trabalho em uma cozinha industrial e distúrbios osteomusculares de trabalhadores. Cadernos de Terapia Ocupacional da UFSCar, São Carlos, v. 21, n. 1, p. 155-162, 2013.

ANJOS, F. B.; MENDES, A. M. A Psicodinâmica do não-trabalho: estudo de caso com concurseiros. Revista Laborativa, Assis, v. 4, n. 1, p. 35-55, 2015.

BENDASSOLI, P. F.; SOBOLL, L. A. P. Clínicas do trabalho: filiaçôes, premissas e desafios. Cadernos de Psicologia Social do Trabalho, Sáo Paulo, v. 14, n. 1, p. 5972, 2011.

BERTIN, C. H. F. et al. O trabalho sob a ótica de manipuladoras de alimentos de uma unidade hospitalar. Revista de Nutrição, Campinas, v. 22, n. 5, p. 643-652, 2009.

BRASIL. Ministério da Educação. Secretaria Municipal de Educação de São Paulo. Departamento de Merenda Escolar da cidade de Sáo Paulo. Normas e padróes básicos para lactários. São Paulo: Secretaria Municipal de Educação, 2010. Disponível em: <http://portalsme.prefeitura. sp.gov.br/Projetos/sitemerenda/Documentos/Manuais_ Folhetos/orienta\%C3\%A7\%C3\%B5es_tecnicas/normas_padroes_lactarios.pdf $>$. Acesso em: 23 jun. 2014.

BRASIL. Ministério da Saúde. Secretaria de Vigilância em Saúde. Departamento de Vigilância em Saúde Ambiental e Saúde do Trabalhador. Dor relacionada ao trabalho: lesōes por esforços repetitivos (LER) e distúrbios osteomusculares relacionados ao trabalho (DORT). Brasília: Ministério da Saúde, 2012. (Série A. Normas e Manuais Técnicos) (Saúde do Trabalhador; 10. Protocolos de Complexidade Diferenciada). Disponível em: < http://bvsms.saude.gov.br/bvs/publicacoes/dor_relacionada_trabalho_ler_dort.pdf>. Acesso em: 18 jan. 2014.

CARUGNO, M. et al. Fatores de risco físico e psicossocial para distúrbios musculoesqueléticos. Cadernos de Saúde Pública, Rio de Janeiro, v. 28, n. 9, p. 1632-1642, 2012.

CARVAlHO, A. T. et al. Programa de alimentação escolar no município de Joáo Pessoa - PB, Brasil. Interface - Comunicação, Saúde, Educação, Botucatu, v. 12, n. 27, p. 823-834, 2008.

CHIAVEGATTO, L. G. F.; PEREIRA, A. J. LER/ DORT: multifatoriedade etiológica e modelos explicativos. Interface - Comunicação, Saúde, Educação, Botucatu, v. 18, n. 14, p. 149-162, 2004.

DEJOURS, C. Subjetividade, trabalho e ação. Revista Produção, São Paulo, v. 14, n. 3, p. 27-34, 2004.

DEJOURS, C. Avaliação do trabalho submetida à prova do real: crítica aos fundamentos da avaliaçáo. São Paulo: Blucher, 2008.

FALZON, P. Natureza, objetivos e conhecimentos da ergonomia. In: FALZON, P. Ergonomia. São Paulo: Blucher, 2007. p. 4-19.

FERNANDES, R. C. P.; ASSUNÇÃO, A. A.; CARVALHO, F. M. Tarefas repetitivas sob pressão temporal: os distúrbios musculoesqueléticos e o trabalho industrial. Ciência \& Saúde Coletiva, Rio de Janeiro, v. 15, n. 3, p. 931-942, 2010.

GALLAGHER, S.; HEBERGER, J. R. Examining the interaction of force and repetition on musculoskeletal disorder risk: a systematic literature review. Human Factors, New York, v. 55, n. 1, p. 15-22, 2013.

GARCIA, R. W. D. A dieta hospitalar na perspectiva dos sujeitos envolvidos em sua produçáo e em seu planejamento. Revista de Nutrição, Campinas, v. 19, n. 2, p. 129-144, 2006.

GUÉRIN, F. et al. Trabalho, tarefa e atividade. In: GUÉRIN, F. et al. Compreender o trabalho para transformá-lo: a prática da ergonomia. São Paulo: Blucher, 2007. p. 11-28.

HUBALT, F.; SZNELWAR, L. I. Can activity be understood out of subjectivity? Work, Netherlands, v. 41, n. 1, p. 26-29, 2012.

ISOSAKI, M. et al. Prevalência de sintomas osteomusculares entre trabalhadores de um serviço de nutriçáo hospitalar em São Paulo. Revista Brasileira de Saúde Ocupacional, São Paulo, v. 36, n. 124, p. 238-246, 2011.

MACDONALD, W.; OAKMAN, J. Requirements for more effective prevention of work-related musculoskele- 
tal disorders. BMC Musculoskeletal Disorders, London, v. 16, p. 293-302, 2015.

MILLANVOYE, M. As ambiências físicas no posto de trabalho. In: FALZON, P. Ergonomia. São Paulo: Blucher, 2007. p. 73-84.

MONTEIRO, M. A. M. Importância da ergonomia na saúde dos funcionários de unidades de alimentação e nutrição. Revista Baiana de Saúde Pública, Salvador, v. 33, n. 3, p. 416-427, 2009.

NEGRI, J. R. et al. Perfil sociodemográfico e ocupacional de trabalhadores com LER/DORT: estudo epidemiológico. Revista Baiana de Saúde Pública, Salvador, v. 38, n. 3, p. 555-570, 2014.

NEVES, R. F; NUNES, M. O. Da legitimação a (re) significação: o itinerário terapêutico de trabalhadores com sintomas osteomusculares. Ciência \& Saúde Coleti$v a$, Rio de Janeiro, v. 15, n. 1, p. 211-220, 2010.

OLIVEIRA, P. A. B. Trabalho coletivo: a construção de espaço de Cooperação e de trocas cognitivas entre os trabalhadores. In: JAQUES, M. G.; CODO, W. Saúde mental \& Trabalho: leituras. Petrópolis: Vozes, 2002. p. 82-97.

SILVA, C. O; RAMMINGER, T. Work as a promoter of health. Ciência \& Saúde Coletiva, Rio de Janeiro, v. 19, n. 12, p. 4751-4758, 2014.

SILVA, E. F.; BRITO, J.; ATHAYDE, M. Trabalho de merendeiras: relaçóes entre atividade de trabalho nas escolas e produção de saúde/doença. In: ARAUJO, A. et al. (Org.). Cenários do trabalho: subjetividade, movimento e enigma. Rio de Janeiro: DP\&A, 2004. p. 89-109.

SOUZA, R. C.; SILVEIRA, F. S. A. Análise Ergonômica do Trabalho (AET) em uma unidade produtora de refeição na cidade de Viçosa, MG. In: SIMPÓSIO DE PRODUÇÃO ACADÊMICA, 3., 2011, Viçosa. Anais... Viçosa: UFV, 2011. p. 32-38.

TAKAHASHI, M. A. B.; PIZZI, C. R.; DINIZ, E. P. H. Nutrição e dor: o trabalho de merendeiras nas escolas públicas de Piracicaba - para além do pão e leite. Revista Brasileira de Saúde Ocupacional, São Paulo, v. 35, n. 122, p. 362-373, 2010.

\section{Contribuição dos Autores}

Maria do Carmo e Janaína trabalharam na concepção do artigo, na revisão e redação final do texto. Ambas as autoras aprovaram a versão final do texto. 